\title{
Тектодинамика Вуоксинской разломной зоны (Карельский перешеек)
}

\author{
Маринин А.В., Сим Л.А., Бондарь И.В. \\ Институт физики Земли им. О.Ю. Шмидта РАН, Москва, marinin@ifz.ru
}

\begin{abstract}
Аннотация. Вдоль зоны Вуоксинского глубинного разлома полевыми тектонофизическими методами определены характеристики напряженно-деформированного состояния массивов горных пород, а также кинематический тип разломов на новейшем этапе. Полученные данные показали в исследованном районе разнообразие ориентировок осей главных нормальных напряжений, среди которых выделены два основных направления максимального сжатия - северо-восточное (до ВСВ) и северо-западное (до ЗСЗ). Для данной зоны преобладает тип напряженного состояния горизонтального сдвига, для которого характерны латеральные сдвиговые перемещения по разломной зоне.

Ключевые слова: Балтийский щит, Вуоксинский разлом, пещеры Иностранцева, тектонические напряжения, тип напряженного состояния, структурные парагенезы, зеркала скольжения, разрывы, отрывы, трещины.
\end{abstract}

\section{Tectodynamics of the Vuoksi Fault Zone in the Karelian Isthmus}

Marinin A.V., Sim L.A., Bondar I.V.

The Schmidt Institute of Physics of the Earth of the RAS, Moscow, marinin@ifz.ru

\begin{abstract}
The characteristics of the stress-and-strain state of rock massifs, as well as the kinematic type of faults at the latest stage are determined by field tectonophysical methods along the Vuoksi deep fault zone. The obtained data showed a variety of orientations of the principal stress axes in the studied area, among which two main directions of maximum compression were identified - NE-SW (to ENE-WSW) and NW-SE (to WNW-ESE). For this zone, the type of stress regime of strike-slip fault prevails, which is characterized by lateral strike-slip fault displacements along the fault zone.
\end{abstract}

Key words: Baltic Shield; Vuoksi fault zone; Inostrantsev Caves; tectonic stress; stress regime; tectonic pattern; slickenside; fault; tension gash; joints.

\section{Введение}

Район исследования относится к южной окраине Балтийского кристаллического щита (Карельский перешеек). В геологическом строении района принимают участие архейские и нижнепротерозойские метаморфические комплексы, представленные биотитовыми, амфиболобиотитовыми и слюдяными гнейсами, а также кристаллическими сланцами с интрузиями кислых и основных пород (Геология..., 1971; Государственная..., 1999). По периферии склонов Балтийского щита выделяется зона долгоживущих разломов и связанное с ними резкое погружение кристаллического фундамента. Данная мобильная зона определяет границу Балтийского щита и его погруженных склонов (Хазов и др., 2004).

Для рассматриваемого района отмечается наличие двух систем планетарных глубинных разломов: ортогональной и диагональной. Они предопределяют форму делимости ее на блоковые элементы. Наиболее четко в изученном районе проявлена диагональная система, которая представлена собственно Вуоксинской разломной зоной северо-западного простирания, разделяющей Выборгский и Приозерский блоки фундамента (рис. 1). Разломы северо-западного простирания в целом совпадают с простиранием осей складок протерозойской складчатой системы. Из ортогональной системы достаточно хорошо выражены зоны субмеридиональных разломов, а субширотные зоны выделяются лишь фрагментарно (Светов и Свириденко, 1991; Хазов и др., 2004).

\section{Цели, методы и материалы исследования}

Целью исследований являлось изучение кинематического типа разрывов, входящих в состав Вуоксинской зоны, реконструкция параметров напряженно-деформированного состояния в массивах горных пород, обрамляющих зону. Собранные данные включают около 300 замеров разнообразных малых структурных форм, в том числе 150 замеров с кинематической информацией на поверх- 


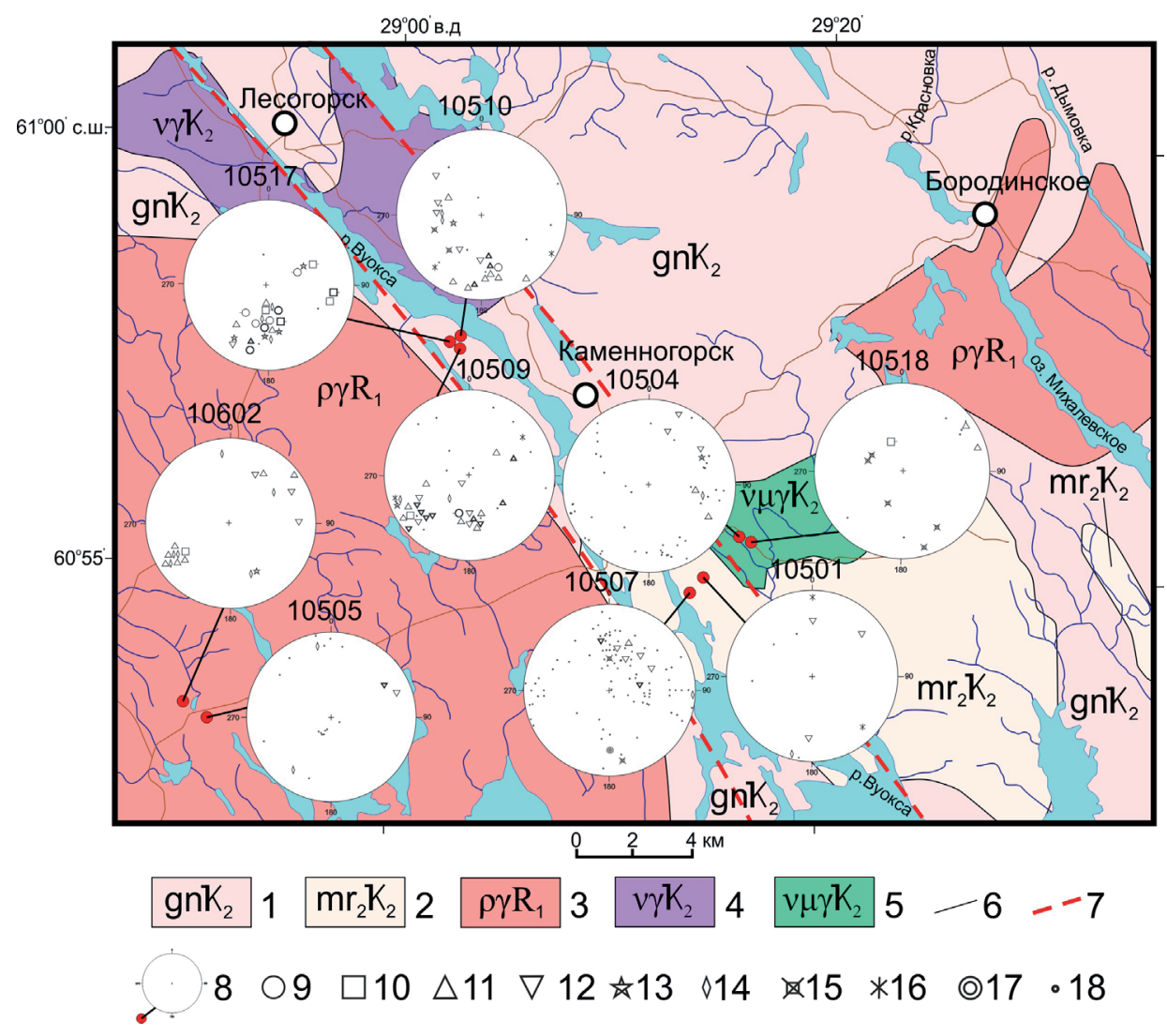

Рис. 1. Карта района исследований с точками наблюдения малых структурных форм.

Составлена с учетом данных (Геология..., 1971; Государственная..., 1999).

1 - метаморфические комплексы верхнего протерозоя; 2 - плутоно-метаморфические комплексы верхнего протерозоя (мигматит-граниты); 3 - интрузивные породы нижнего рифея (граниты-рапакиви); 4 - интрузивные породы верхнего протерозоя (габбро, габбродиориты, реже граниты); 5 - интрузивные породы верхнего протерозоя (габбро, монцогаббро, диориты, монцониты, сиениты, граниты); 6 - геологические границы; 7 - зона Вуоксинской разломной зоны; 8 - точки наблюдения и круговые диаграммы в стереографической проекции на верхнюю полусферу с полюсами малых структурных форм (с преимущественным типом перемещений): 9 - взбросы, 10 - сбросы, 11 - правые сдвиги, 12 - левые сдвиги, 13 - перемещения взбросовые или сбросовые (по падению/восстанию), 14 - сдвиги (без определения относительного перемещения), 15 - отрывы, 16 - жилы, 17 - зоны дробления, 18 - трещины.

Fig. 1. Map of the study area with observation points of small structural forms.

Compiled with data (Геология..,, 1971; Государственная..., 1999).

1 - metamorphic complexes of the Upper Proterozoic; 2 - pluto-metamorphic complexes of the Upper Proterozoic (migmatite-granites); 3 - Intrusive rocks of the lower Riphean (granites-rapakivi); 4 - intrusive rocks of the Upper Proterozoic (gabbro, gabbrodiorites, less often granites); 5 - intrusive rocks of the Upper Proterozoic (gabbro, monzonites, syenites, granites); 6 - geological boundaries; 7 - area of the Vuoksi fault zones; 8 - the observation points and stereoplots (stereographic projection on the upper hemisphere) with the poles of small structural forms and its kinematic types: 9 - reverse faults and trusts, 10 - normal faults, 11 - dextral strike-slip faults, 12 - sinistral strike-slip faults, 13 - dip-slip fault, 14 - strike-slip faults, 15 - tension gashes, 16 - veins, 17 - crush zone, 18 - joints.

ности разрывных нарушений (рис. 1). Помимо замеров полевые материалы включают зарисовки и фотографии различных геологических структур. При анализе систем тектонической трещиноватости разных кинематических типов с их объединением в устойчивые структурные ассоциации (парагенезы) применен структурно-парагенетический метод Л.М. Расцветаева (1987). Обработка данных полевых замеров геологических стресс-индикаторов проводилась с помощью метода катакластического анализа Ю.Л. Ребецкого (2007). Для реконструкции напряженно-деформированного состояния использовалась программа STRESSgeol, разработанная в лаборатории тектонофизики ИФЗ РАН 


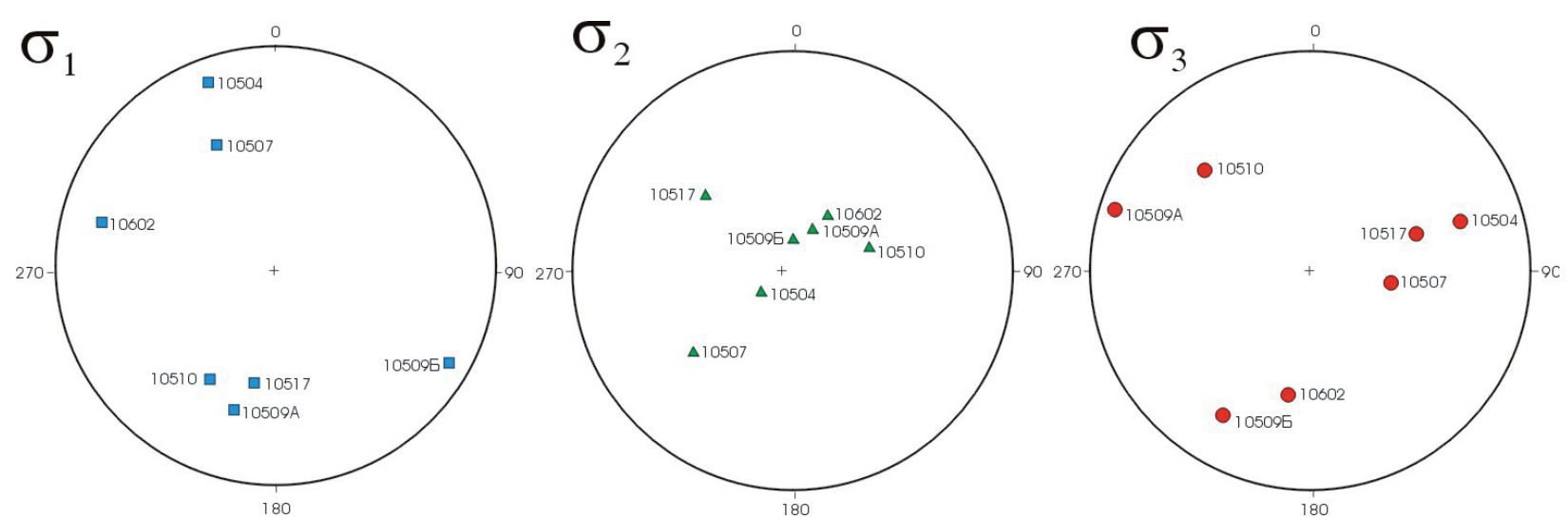

Рис. 2. Ориентировка осей главных напряжений локальных стресс-тензоров Вуоксинской разломной зоны. На круговых диаграммах (стереографическая проекция на верхнюю полусферу) показаны выходы осей главных напряжений: $\sigma_{1}$ - минимальных (девиаторное растяжение), $\sigma_{2}-$ промежуточных и $\sigma_{3}-$ максимальных сжимающих напряжений. Номерами показаны точки наблюдения, в которых реконструированы характеристики локальных стресс-тензоров.

Fig. 2. The orientation of principal stress axes of the local stress tensors of the Vuoksi fault zone. Stereoplots (stereographic projection on the upper hemisphere) show the outputs of the principal stress axes: $\sigma_{1}$ - minimum (deviatoric tension), $\sigma_{2}$ - intermediate and $\sigma_{3}$ - maximum compressive stresses. The numbers show observation points in which the characteristics of local stress tensors are reconstructed.

и использующая алгоритмы вышеуказанного метода (Ребецкий и др., 2017). Метод катакластического анализа позволяет определить количественные характеристики реконструируемых локальных стресс-состояний: положение осей главных напряжений/деформаций и коэффициент Лоде - Надаи.

\section{Результаты реконструкции тектонических напряжений}

Полученные ориентации осей главных нормальных напряжений характеризуются значительным разбросом. Условно преобладающей для осей максимального сжатия можно назвать запад - северо-западную (3 определения) вплоть до субширотной ориентировку (рис. 2). Кроме того, ряд определений характеризуются северо-восточным направлением оси максимального сжатия. У промежуточных осей $\left(\sigma_{2}\right)$ преобладают субвертикальные ориентировки (4 определения). Среди осей максимального девиаторного растяжения преобладает субгоризонтальное север - северо-восточное погружение. В двух точках наблюдения оси растяжения погружаются в юг - юго-восточном направлении (рис. 2). По результатам реконструкции установлено, что для рассматриваемого района преобладают обстановки горизонтального сдвига, но встречаются и обстановки горизонтального растяжения в сочетании со сдвигом. Кинематический тип Вуоксинских разломов с помощью метода поясного распределения трещиноватости установлен как правый сдвиг, что подтверждается изучением палеосейсмодислокаций в районе пещер Иностранцева, где по разлому северо-западного простирания восстановлено современное правостороннее перемещение (Никонов и др., 2014).

Полученная изменчивость направлений максимально сжатия соотносится с зоной «неустойчивых тектонических напряжений», выделенной ранее для Восточно-Европейской платформы (Сим, 2000). Допускается, что это обусловлено вхождением этого участка Балтийского щита в зону с двойными ориентациями осей сжатия, выделенную вдоль побережья Балтийского залива. В этой зоне разломы могут быть как правыми сдвигами, так и левыми, т.е. ориентировка оси сжатия может в этой области меняться от меридиональной до субширотной, что предположительно вызвано поочередной активизацией меридионального Ботнического и широтного Финского заливов (Сим, 2000). Двойные неустойчивые ориентировки осей сжатия в этом районе подтверждаются и механизмами очагов землетрясений: по Осмуссаарскому событию восстановлена широтная ось сжатия, а в Калининградских - меридиональная.

Доминирование субгоризонтальных осей максимального сжатия и растяжения говорит о том, что в целом поле напряжений Вуоксинской зоны близко по типу напряженного состояния к 
горизонтальному сдвигу, что характерно для Карельского и Ковдорского полигона Балтийского щита (Сим, 2000; Сим и др., 2011) (табл. 1). На этих полигонах поле напряжений реконструировано по более чем 1000 замеров зеркал скольжения с установленными векторами перемещений, в то время как в Вуоксинской зоне локальные стресс-тензоры восстановлены всего по 150 измерениям. Сдвиговые поля тектонических напряжений на Карельском и Ковдорском полигонах восстановлены достаточно уверенно, при этом оси максимального сжатия локальных стресс-состояний на обоих полигонах ориентированы преимущественно в ЗС3 направлении, а оси растяжения - в субмеридиональном направлении. В пределах Хибинского массива также наиболее проявлено запад - северо-западное направление максимального сжатия, но уже в обстановке горизонтального сжатия и сдвига (Маринин и др., 2018).

Таблица 1. Параметры реконструированного напряженно-деформированного состояния в области Вуоксинской разломной зоны.

Table 1. Parameters of the reconstructed stress-and-strain state in the area of the Vuoksinskie fault zone.

\begin{tabular}{|c|c|c|c|c|c|c|c|c|c|c|c|c|}
\hline & Номер & $\begin{array}{r}\text { Координ } \\
\text { набль }\end{array}$ & $\begin{array}{l}\text { Ы точек } \\
\text { ения }\end{array}$ & $\sigma_{1}$ & & $\sigma$ & & $\sigma_{3}$ & & Тип & & Э Ттап \\
\hline & & с.ш. & в.д. & Аз Пд & $\angle$ & Аз Пд & $\angle$ & Аз Пд & $\angle$ & & & \\
\hline 1 & 10602 & $60^{\circ} 51.06^{\prime}$ & $28^{\circ} 51.67^{\prime}$ & 106 & 12 & 215 & 57 & 9 & 30 & $\begin{array}{l}\text { горизонтальный } \\
\text { сдвиг }\end{array}$ & 0.22 & 1 \\
\hline 2 & $10509 A$ & $60^{\circ} 58.36^{\prime}$ & $29^{\circ} 03.04^{\prime}$ & 16 & 23 & 210 & 66 & 108 & 5 & $\begin{array}{l}\text { горизонтальный } \\
\text { сдвиг }\end{array}$ & -0.02 & $2(\mathrm{~A})$ \\
\hline 3 & 10509Б & & & 298 & 6 & 187 & 74 & 30 & 15 & $\begin{array}{l}\text { горизонтальный } \\
\text { сдвиг }\end{array}$ & -0.15 & $2($ Б) \\
\hline 4 & 10510 & $60^{\circ} 58.37^{\prime}$ & $29^{\circ} 03.00^{\prime}$ & 30 & 31 & 255 & 50 & 134 & 23 & $\begin{array}{l}\text { горизонтальный } \\
\text { сдвиг }\end{array}$ & -0.1 & 1 \\
\hline 5 & 10517 & $60^{\circ} 58.37^{\prime}$ & $29^{\circ} 02.75^{\prime}$ & 10 & 36 & 131 & 35 & 250 & 35 & $\begin{array}{l}\text { горизонтальное } \\
\text { сжатие }\end{array}$ & -0.09 & 1 \\
\hline 6 & 10507 & $60^{\circ} 53.40^{\prime}$ & $29^{\circ} 12.69^{\prime}$ & 156 & 26 & 50 & 30 & 279 & 49 & $\begin{array}{l}\text { горизонтальное } \\
\text { растяжение }\end{array}$ & 0.08 & 1 \\
\hline 7 & 10504 & $60^{\circ} 54.33^{\prime}$ & $29^{\circ} 14.80^{\prime}$ & 161 & 6 & 54 & 71 & 252 & 18 & $\begin{array}{l}\text { горизонтальный } \\
\text { сдвиг }\end{array}$ & -0.12 & 1 \\
\hline
\end{tabular}

Примечание. В столбцах указано название участка, в пределах которой располагается точка наблюдения; номер и координаты точки наблюдения; реконструированные при помощи метода катакластического анализа (Ребецкий, 2007) по структурно-кинематическим данным о трещинах ориентировки осей главных напряжений ( $\sigma_{1}-$ минимальных (девиаторное растяжение), $\sigma_{2}$ - промежуточных и $\sigma_{3}-$ максимальных сжимающих напряжений); тип (обстановка) напряженного состояния; коэффициент Лоде - Надаи $\mu \sigma ;$ количество этапов деформирования.

\section{Заключение}

Тектонофизические исследования в Вуоксинской разломной зоне показали неустойчивость ориентировок осей максимального сжатия и растяжения локальных стресс-тензоров. Полученные данные по кинематике малых структурных форм и реконструкции напряженно-деформированного состояния горных пород региона свидетельствуют о геодинамической обстановке горизонтального сдвига и преобладании латеральных перемещений по разрывным нарушениям. Системы сдвиговых нарушений, фиксируемых вблизи Вуоксинской разломной зоны, говорят о близости их ориентировки с простиранием собственно этой зоны и преобладании правосдвиговой кинематики.

Исследование выполнено при финансовой поддержке гранта РФФИ 17-05-01193а.

\section{Литература}

1. Геология СССР. Т. 1. Геологическое описание. Ленинградская, Псковская и Новгородская области. М.: Недра, $1971.504 \mathrm{c}$.

2. Государственная геологическая карта РФ. Сер. Карельская. 1 : 200 000. Лист Р-35-XXIX, XXX. Утвержден НРС ВСЕГЕИ 09.06.1999. СПб. 
3. Маринин А.В., Сим Л.А., Жиров Д.В., Бондарь И.В. Структурные парагенезы и тектонические напряжения южной части Хибинского массива // Труды Ферсмановской научной сессии ГИ КНЦ РАН. 2018. № 15. C. 239-241.

4. Никонов А.А., Шварев С.В., Сим Л.А., Родкин М.В., Бискэ Г.С., Маринин А.В. Скальные палеосейсмодеформации на Карельском перешейке (ключевой участок «пещеры Иностранцева». Ленинградская область). Доклады РАН. 2014. Т. 457. № 5. С. 591-596.

5. Расцветаев Л.М. Парагенетический метод структурного анализа дизъюнктивных тектонических нарушений. Проблемы структурной геологии и физики тектонических процессов. М.: ГИН АН СССР. 1987. Ч. 2. С. 173-235.

6. Ребецкий Ю.Л. Тектонические напряжения и прочность горных массивов. М.: Изд-во: Наука. 2007.406 с.

7. Ребецкий Ю.Л., Сим Л.А., Маринин А.В. От зеркал скольжения к тектоническим напряжениям. Методы и алгоритмы / Ю.Л. Ребецкий, Л.А. Сим, А.В. Маринин; отв. редактор Ю.Г. Леонов; Институт физики Земли им. О.Ю. Шмидта РАН. Москва: Изд-во ГЕОС. 2017. 225 с.

8. Светов А.П., Свириденко Л.П. Магматизм шовных зон Балтийского щита. Л. Изд-во: Наука. 1991.200 с.

9. Сим Л.А., Жиров Д.В., Маринин А.В. Реконструкция напряженно-деформированного состояния восточной части Балтийского щита // Геодинамика и тектонофизика. 2011. Т. 2. № 3. С. 219-243.

10. Сим Л.А. Влияние глобального тектогенеза на новейшее напряженное состояние платформ Европы // М.В. Гзовский и развитие тектонофизики. М. Изд-во: Наука. 2000. С. 326-350.

11. Хазов Р.А., Шаров Н.В., Исанина Э.В. Глубинное строение и металлогения Приладожья // Геология и полезные ископаемые Карелии. Вып. 7. Петрозаводск. 2004. С. 55-74. 